\title{
A Two-Phase Fuzzy Mining and Learning Algorithm for Adaptive Learning Environment
}

\author{
Chang-Jiun Tsai, S. S. Tseng*, and Chih-Yang Lin \\ Department of Computer and Information Science \\ National Chiao Tung University \\ Hsinchu 300, Taiwan, R.O.C. \\ E-mail: sstseng@cis.nctu.edu.tw
}

\begin{abstract}
As computer-assisted instruction environment becomes more popular over the world, the analysis of historical learning records of students becomes more important. In this work, we propose a Two-Phase Fuzzy Mining and Learning Algorithm, integrating data mining algorithm, fuzzy set theory, and look ahead mechanism, to find the embedded information, which can be provided to teachers for further analyzing, refining or reorganizing the teaching materials and tests, from historical learning records.
\end{abstract}

Keywords: Fuzzy set theory, Data Mining, Machine Learning, CAI

\section{Introduction}

As Internet becomes more popular over the world, the amounts of teaching materials on WWW are increasing rapidly and many students learn knowledge through WWW. Therefore, how to design and construct computer-assisted instruction environment together with its teaching materials is of much concern. In recent years, an adaptive learning environment [13], [14], [15] has been proposed to offer different teaching materials for different students in accordance with their aptitudes and evaluation results. After students learn the teaching materials through the adaptive learning environment, the teachers can further analyze the historical learning records and refine or reorganize the teaching materials and tests.

In this work, we propose a Two-Phase Fuzzy Mining and Learning Algorithm to find the embedded information within the historical learning records for teachers to further analyze, reorganize and refine the learning path of teaching materials or tests. The first phase of proposed algorithm uses a fuzzy data mining algorithm, Look Ahead Fuzzy Mining Association Rule Algorithm (LFMAlg), integrating association rule mining algorithm, Apriori [1], fuzzy set theory, and look ahead mechanism, to find the embedded association rules from the historical learning records of students. The output of this phase can be fed back to teachers for reorganizing the tests, and will be treated as the input of the second phase. The second phase uses an inductive learning algorithm, $\mathrm{AQR}$ algorithm, to find the concept descriptions indicating the missing concepts during students learning. The results of this phase can be provided to teachers for further analyzing, refining or reorganizing the learning path.

\footnotetext{
*Corresponding author 
Some related works and our motivation are first described in Section 2. Section 3 presents the framework of analyzing the historical learning records. Section 4 shows the algorithms. Concluding remarks are given in Section 5.

\section{Related Works and Motivation}

The web-based educational systems are becoming more and more popular over the world. Several approaches, which can be used to organize the teaching materials, have been developed in the past ten years [2], [3], [7], [10], [12]. As to the evaluation, [7] provides the evaluation mechanism to find out what instructional objectives in some sections the students do not learn well. However, the students always need to learn all teaching materials in each section for the first time no matter how the teaching materials are suitable for them or not. Therefore, an adaptive learning environment was proposed in [13] and [14], which can offer different teaching materials for different students in accordance with their aptitudes and evaluation results. The idea is to segment the teaching materials into teaching objects that is called Object-Oriented Course Framework as shown in Figure 1 The teaching materials can be constructed by organizing these teaching objects according to learning path, which can be defined and provided by teachers or teaching materials editors for students learning.

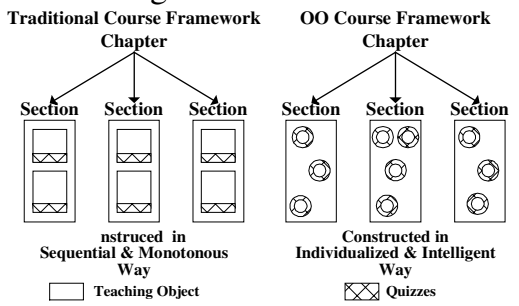

Fig. 1. The comparison between traditional and OO course framework

The architecture of adaptive learning environment is shown in Fig. 2. All teaching objects are stored in Teaching Object Resource Database. When teachers want to construct the teaching materials about some subjects, they can retrieve the teaching objects from Teaching Object Resource Database, and define the learning path about these teaching objects.

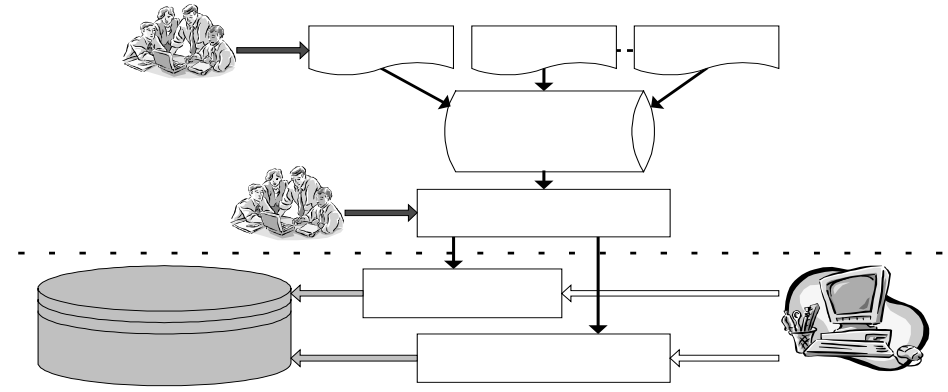

Fig. 2. The architecture of adaptive learning environment

As we know, the learning path is usually defined as tree structure containing some teaching materials, and each teaching object of teaching materials may contain 
the teaching content and quizzes or tests to discriminate the students' learning performance. Therefore, students can learn these teaching materials by following the learning path. For the example of learning path shown in Fig. 3, there is a specific subject of teaching material including four teaching objects, A, B, C, and D. That means $\mathrm{A}$ is the pre-requisite knowledge of B and C. In other words, students should first learn teaching object $\mathrm{A}$, learn teaching objects $\mathrm{B}$ and $\mathrm{C}$, and finally learn teaching object $\mathrm{D}$.

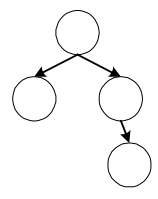

Fig. 3. An example of learning path

All learning records, which are stored into Historical Learning Record Database, would be used in the adaptive learning environment. In other words, the system would reconstruct the course framework according to these learning records for students learning again, if students cannot learn well about the teaching material [14]. Besides, the learning records also can be used to refine the learning path by teachers. Because each quiz or test may consist of more than one concept, some embedded information about the relationships among the high grades of quizzes and low grades of quizzes can be used to determine whether the previously defined learning path is reasonable or not. Therefore, we propose a Two-Phase Fuzzy Mining and Learning Algorithm to find the embedded information about relationships among the learning records.

\section{The Flow of Two-Phase Fuzzy Mining and Learning Algorithm}

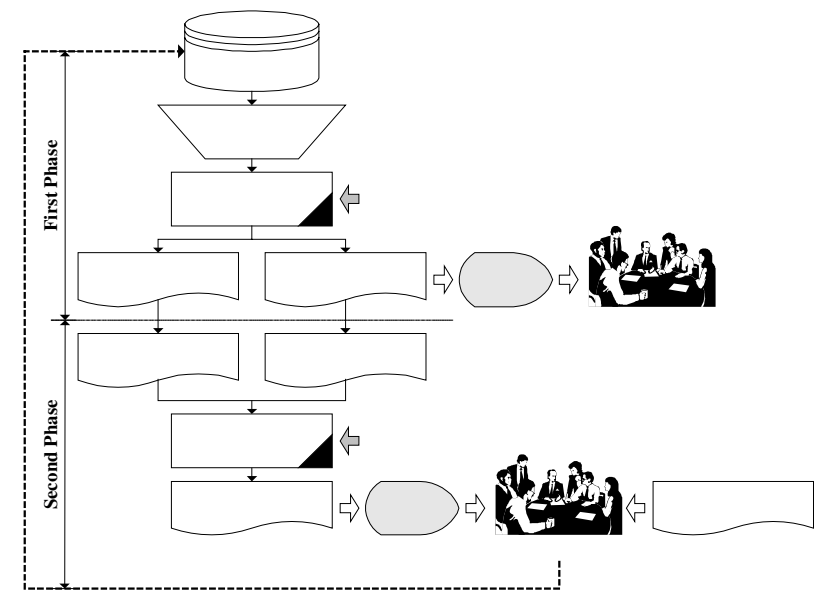

Fig. 4. The flow of Two-Phase Fuzzy Mining and Learning Algorithm

Fig. 4 shows the flow of our Two-Phase Fuzzy Mining and Learning Algorithm, which can provide teachers the some embedded information for further analyzing, refining and reorganizing the learning path and the tests. 


\section{Two-Phase Fuzzy mining and Learning Algorithm}

Input: The learning records of students from Historical Learning Record Database. Output: The information of missing concepts.

Phase1: Use Look Ahead Fuzzy Mining Association Rule Algorithm to find the fuzzy association rules of quizzes from the historical learning records.

Phase2: Use Inductive Learning Algorithm to find the missing concept during students learning.

The first phase, data mining phase, applies fuzzy association rule mining algorithm to find the associated relationship information, which is embedded in learning records of students. In Table1, there are ten learning records of students, and each record has the grades of 5 quizzes, where the highest grade of each quiz is 20 .

Table 1. An example of students' learning record

\begin{tabular}{|c|c|c|c|c|c|c|}
\hline Student ID & $\overline{Q_{1}}$ & $\mathbf{Q}_{2}$ & $\overline{Q_{3}}$ & $\overline{\mathbf{Q}_{4}}$ & $\mathbf{Q}_{5}$ & Total \\
\hline 1 & 12 & 14 & 18 & 3 & 9 & $56 / 100$ \\
\hline 2 & 10 & 6 & 12 & 6 & 7 & $41 / 100$ \\
\hline 3 & 3 & 6 & 6 & $\mathbf{1}$ & 5 & $21 / 100$ \\
\hline 4 & 8 & 10 & 8 & 2 & 8 & $36 / 100$ \\
\hline 5 & 16 & 18 & 20 & 20 & 20 & $94 / 100$ \\
\hline 6 & $\mathbf{0}$ & 3 & 3 & 1 & 4 & $11 / 100$ \\
\hline 7 & 1 & 8 & 6 & 4 & 10 & $29 / 100$ \\
\hline 8 & 2 & 3 & 3 & $\mathbf{0}$ & 3 & $11 / 100$ \\
\hline 9 & 12 & 16 & 14 & 4 & 14 & $60 / 100$ \\
\hline 10 & 6 & 8 & 12 & 2 & 10 & $38 / 100$ \\
\hline
\end{tabular}

Assume each quiz may contain one or more learning concepts. As shown in Table 2, related learning concepts A, B, C, D, and E may be contained in these five quizzes, where " 1 " indicates the quiz contains this concept, and " 0 " indicates not.

Table 2. An example of learning concepts information

\begin{tabular}{||c|c|c|c|c|c||}
\hline \hline & $\mathrm{A}$ & $\mathrm{B}$ & $\mathrm{C}$ & $\mathrm{D}$ & $\mathrm{E}$ \\
\hline $\mathrm{Q}_{1}$ & 1 & 0 & 0 & 1 & 0 \\
\hline $\mathrm{Q}_{2}$ & 1 & 0 & 1 & 0 & 0 \\
\hline $\mathrm{Q}_{3}$ & 1 & 0 & 0 & 0 & 0 \\
\hline $\mathrm{Q}_{4}$ & 0 & 1 & 1 & 0 & 0 \\
\hline $\mathrm{Q}_{5}$ & 0 & 1 & 0 & 0 & 1 \\
\hline
\end{tabular}

Assume most students get the low grades for $\mathrm{Q}_{1}$ and $\mathrm{Q}_{2}$, and thus $\mathrm{Q}_{1}$ may associate with $\mathrm{Q}_{2}$. This means for students missing the learning concept of $\mathrm{Q}_{1}(\mathrm{~A}, \mathrm{D})$, they may also miss the learning concept of $\mathrm{Q}_{2}(\mathrm{~A}, \mathrm{C})$. The fuzzy association rule mining algorithm is then used to find the embedded information about the relationships among the low grades of quizzes and the relationships among the high grades of quizzes. These embedded information can be viewed as the positive and negative instances, which will be the input of the second phase. In addition, the obtained embedded information can be provided to teachers for making up appropriate quizzes. Accordingly, we can suggest that at most one of $\mathrm{Q}_{1}$ and $\mathrm{Q}_{2}$ should be included in the same test to improve the discriminative ability, if there exists the association relationship between $\mathrm{Q}_{1}$ and $\mathrm{Q}_{2}$.

The second phase is to find the missing concepts for most students. We apply inductive learning strategy, AQR learning algorithm [8] which is suitable for symbolic learning, to include all positive instances and exclude all negative instances. Then the teachers can refine learning path according to these information and original 
learning path. As mentioned above, in Table 2, the $\mathrm{Q}_{1}(\mathrm{~A}, \mathrm{D})$ and $\mathrm{Q}_{2}(\mathrm{~A}, \mathrm{C})$ belong to the set of low grades of quizzes. Thus the set of missing concepts, (A, C, D), can be regarded as a positive instance for $\mathrm{AQR}$ learning algorithm. On the contrary, the set of hitting concepts can be regarded as the negative instance. By using AQR algorithm for these training instances, some rules which can include all positive instances and exclude all negative instances can be learned.

\section{Algorithm}

In this section, Look Ahead Fuzzy Mining Association Rule Algorithm (LFMAlg) used in the first phase and $\mathrm{AQR}$ algorithm used in the second phase will be described.

\subsection{Fuzzy Data Mining Algorithm}

IBM Almaden Research Center proposed the association rule mining algorithm, Apriori algorithm [1], to find the embedded information within a large number of transactions. The famous example of supermarket shows trend of buying behavior of customers. Unfortunately, the Apriori algorithm only works in ideal domains where all data are symbolic and no fuzzy data are present. However, real-world applications sometimes contain some numeric information, which need to be transformed into symbolic. For example, if the grade of quiz is 78 , different experts may have different opinions of the concept "high grade". Thus, how to transform the linguistic data into the symbolic data and how to let Apriori algorithm be able to handle numeric information of these linguistic data are of most importance. Our idea is to improve Apriori algorithm by applying fuzzy set theory to overcome the problem of existing fuzzy regions among the data.

A fuzzy set is an extension of a crisp set, which allows only full membership or no membership at all, whereas fuzzy set allows partial membership. To apply fuzzy concepts, the membership function of each quiz's grade, which can transform numeric data into fuzzy set, is defined in Fig. 5.

As we know, in the association rule mining algorithm, the support of association rule is larger than a minimum support threshold, defines as $\alpha_{\ell}$, and the confidence of association rule is larger than a minimum confidence threshold, defined as $\lambda$, in $\ell$ large itemset. In Apriori algorithm, $\alpha_{\ell}$ is a constant, and then the number of association rules may decrease when $\ell$ increases in $\ell$-large itemset. That may cause losing of some association rules in larger itemsets. However the minimum support threshold may be too small to exhibit the meaning of association rule. Hence, we apply Look Ahead mechanism to generate Next Pass Large Sequence [6] to overcome the above problem.

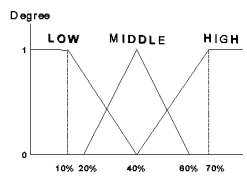

Fig. 5. The given membership function of each quiz's grade

As mentioned above, we proposed the Look Ahead Fuzzy Mining Association Rule Algorithm, integrating Apriori algorithm, Look Ahead mechanism, and Fuzzy Set Theory, to find the association rules within fuzzy data set as below. 


\section{Definition}

$f_{i j}(k)$ : indicates the $k^{\text {th }}$ student's fuzzy values for the $i^{\text {th }}$ quiz and the $j^{\text {th }}$ degree of fuzzy function.

$F_{i j}$ : indicates the sum of all students' fuzzy value for the $i^{\text {th }}$ quiz and the $j^{\text {th }}$ degree of fuzzy function, i.e., $F_{i j}=\sum_{k=1}^{n} f_{i j}(k)$, where $n$ indicates the number of students. $C_{\ell}$ : indicates $\ell$-candidate itemset.

$N P L S_{\ell}$ : indicates $\ell$-Next Pass Large Sequence (NPLS) [6].

$L_{\ell}$ : indicates $\ell$-large itemset.

$\alpha_{\ell}$ : indicates the minimum support threshold of $\ell$-large itemset. $\operatorname{support}(x)$ : indicates the support values of the element $x$ for $x \in C_{\ell}$.

\section{Look Ahead Fuzzy Mining Association Rule Algorithm}

Input: The learning records of students from Historical Learning Record Database.

The minimum support threshold $\alpha_{1}$ in the 1-large itemset, $L_{1}$.

The minimum confidence threshold $\lambda$.

Output: The fuzzy association rules of learning records of students.

STEP1: Transform the grades of each quiz into fuzzy value, $f_{i j}(k)$, for all students according to the fuzzy membership function.

STEP2: $C_{1}=\left\{F_{i j} \mid F_{i j}=\sum_{k=1}^{n} f_{i j}(k)\right\}$, and $\ell=1$

STEP3: $L_{\ell}=\left\{x \mid \operatorname{support}(x) \geq \alpha_{\ell}, \quad\right.$ for $\left.\quad x \in C_{\ell}\right\}$

STEP4: $\alpha_{\ell+1}=\max \left(\frac{\alpha_{1}}{2}, \alpha_{\ell}-\frac{\alpha_{1}}{\ell * c}\right)$, where $c$ is a constant .

STEP5: $N P L S_{\ell}=\left\{x \mid \operatorname{support}(x) \geq \alpha_{\ell+1}, \quad\right.$ for $\left.\quad x \in C_{\ell}\right\}$

STEP6: If $N P L S_{\ell}$ is null,

then stop the mining process and go to STEP8,

else generate the $(\ell+1)$-candidate set, $C_{\ell+1}$, from $N P L S_{\ell}$.

STEP7: $\ell=\ell+1$ and go to STEP3.

STEP8: Determine the association rules according to the given $\lambda$ and all large itemsets.

\section{Example 4.1}

According to the given membership function defined in Fig. 5, Table 3 shows the fuzzication result of the data of Table 1. The "Low" denotes "Low grade ", "Mid" denotes "Middle grade", and "High" denotes "High grade". $Q_{i} . L$ denotes the low degree of fuzzy function of the $i^{\text {th }}$ quiz, $Q_{i} \cdot M$ denotes the middle degree of fuzzy function of the $i^{\text {th }}$ quiz, and $Q_{i} \cdot H$ denotes the high degree of fuzzy function of the $i^{\text {th }}$ quiz. 
Table 3. The fuzzication results of the data of Table 1

\begin{tabular}{|c|c|c|c|c|c|}
\hline Student ID & $\begin{array}{c}Q_{I} \\
\text { Low Mid High }\end{array}$ & $\begin{array}{c}Q_{2} \\
\text { Low Mid High }\end{array}$ & $\begin{array}{c}Q_{3} \\
\text { Low Mid High }\end{array}$ & $\begin{array}{c}Q_{4} \\
\text { Low Mid High }\end{array}$ & $\begin{array}{c}Q_{5} \\
\text { Low Mid High }\end{array}$ \\
\hline 1 & $\begin{array}{llll}0.0 & 0.0 & 0.7\end{array}$ & $\begin{array}{lll}0.0 & 0.0 & 1.0\end{array}$ & $\begin{array}{lll}0.0 & 0.0 & 1.0\end{array}$ & $\begin{array}{lll}0.8 & 0.0 & 0.0\end{array}$ & $\begin{array}{lll}0.0 & 0.8 & 0.2\end{array}$ \\
\hline 2 & $\begin{array}{llll}0.0 & 0.5 & 0.3 \\
\end{array}$ & $\begin{array}{llll}0.3 & 0.5 & 0.0 \\
\end{array}$ & $\begin{array}{llll}0.0 & 0.0 & 0.7\end{array}$ & $\begin{array}{llll}0.3 & 0.5 & 0.0 \\
\end{array}$ & $\begin{array}{llll}0.2 & 0.8 & 0.0 \\
\end{array}$ \\
\hline 3 & $\begin{array}{lll}0.8 & 0.0 & 0.0\end{array}$ & $\begin{array}{llll}0.3 & 0.5 & 0.0\end{array}$ & $\begin{array}{llll}0.3 & 0.5 & 0.0\end{array}$ & $\begin{array}{lll}.0 & 0.0 & 0.0\end{array}$ & $\begin{array}{lll}0.5 & 0.3 & 0.0 \\
\end{array}$ \\
\hline 4 & $\begin{array}{llll}0.0 & 1.0 & 0.0\end{array}$ & $\begin{array}{llll}0.0 & 0.5 & 0.3 \\
\end{array}$ & $\begin{array}{llll}0.0 & 1.0 & 0.0 \\
\end{array}$ & $\begin{array}{lll}1.0 & 0.0 & 0.0 \\
\end{array}$ & $\begin{array}{llll}0.0 & 1.0 & 0.0 \\
\end{array}$ \\
\hline 5 & $\begin{array}{lll}0.0 & 0.0 & 1.0\end{array}$ & $\begin{array}{llll}0.0 & 0.0 & 1.0\end{array}$ & $\begin{array}{lll}0.0 & 0.0 & 1.0\end{array}$ & $\begin{array}{llll}0.0 & 0.0 & 1.0\end{array}$ & $\begin{array}{lll}0.0 & 0.0 & 1.0\end{array}$ \\
\hline 6 & $\begin{array}{lll}1.0 & 0.0 & 0.0\end{array}$ & $\begin{array}{lll}0.8 & 0.0 & 0.0\end{array}$ & $\begin{array}{llll}0.8 & 0.0 & 0.0\end{array}$ & $\begin{array}{lll}1.0 & 0.0 & 0.0\end{array}$ & $\begin{array}{lll}0.7 & 0.0 & 0.0\end{array}$ \\
\hline 7 & $\begin{array}{lll}1.0 & 0.0 & 0.0\end{array}$ & $\begin{array}{llll}0.0 & 1.0 & 0.0\end{array}$ & $\begin{array}{lll}0.3 & 0.5 & 0.0\end{array}$ & $\begin{array}{lll}0.7 & 0.0 & 0.0\end{array}$ & $\begin{array}{llll}0.0 & 0.5 & 0.3\end{array}$ \\
\hline 8 & $\begin{array}{lll}1.0 & 0.0 & 0.0\end{array}$ & $\begin{array}{lll}0.8 & 0.0 & 0.0\end{array}$ & $\begin{array}{lll}0.8 & 0.0 & 0.0\end{array}$ & $\begin{array}{lll}1.0 & 0.0 & 0.0\end{array}$ & $\begin{array}{lll}0.8 & 0.0 & 0.0\end{array}$ \\
\hline 9 & $\begin{array}{llll}0.0 & 0.0 & 0.7\end{array}$ & $\begin{array}{lll}0.0 & 0.0 & 1.0\end{array}$ & $\begin{array}{lll}0.0 & 0.0 & 1.0\end{array}$ & $\begin{array}{lll}0.7 & 0.0 & 0.0\end{array}$ & $\begin{array}{lll}0.0 & 0.0 & 1.0\end{array}$ \\
\hline 10 & $\begin{array}{lll}0.3 & 0.5 & 0.0 \\
\end{array}$ & $\begin{array}{llll}0.0 & 1.0 & 0.0 \\
\end{array}$ & $\begin{array}{llll}0.0 & 0.0 & 0.7 \\
\end{array}$ & $\begin{array}{llll}1.0 & 0.0 & 0.0 \\
\end{array}$ & $\begin{array}{llll}0.0 & 0.5 & 0.3 \\
\end{array}$ \\
\hline
\end{tabular}

According to the fuzzy data shown in Table 3, Fig. 6 shows the process of finding the association rules for the original data shown in Table 1. In this case, assume $\alpha_{1}=2.1$ and $\lambda=0.75$. Table 4 shows the process of calculating the confidence of 2-large itemset. For example, the confidence value of the itemset $\left(\mathrm{Q}_{2} . \mathrm{L}\right.$, $\mathrm{Q}_{1} . \mathrm{L}$ ) is 0.86 , means that many students get low grades of $\mathrm{Q}_{1}$ and $\mathrm{Q}_{2}$ simultaneously. The embedded information shows that $\mathrm{Q}_{1}$ may have similar property or may contain similar learning concept with $\mathrm{Q}_{2}$. Therefore, we may suggest that $\mathrm{Q}_{1}$ and $\mathrm{Q}_{2}$ do not appear at the same test.

Table 4. The process of calculating the confidence of 2-large itemset

\begin{tabular}{|c|c|c|c|}
\hline Itemset & Confidence & Itemset & Confidence \\
\hline$\left(\mathrm{Q}_{1} . \mathrm{L}, \mathrm{Q}_{2} . \mathrm{L}\right)$ & 0.46 & $\left(\mathrm{Q}_{1} \cdot \mathrm{H}, \mathrm{Q}_{2} \cdot \mathrm{H}\right)$ & 0.89 \\
\hline$\left(\mathrm{Q}_{2} \cdot \mathrm{L}, \mathrm{Q}_{1} \cdot \mathrm{L}\right)$ & 0.86 & $\left(\mathrm{Q}_{2} \cdot \mathrm{H}, \mathrm{Q}_{1} \cdot \mathrm{H}\right)$ & 0.72 \\
\hline$\left(\mathrm{Q}_{1} \cdot \mathrm{L}, \mathrm{Q}_{3} . \mathrm{L}\right)$ & 0.54 & $\left(\mathrm{Q}_{1} \cdot \mathrm{H}, \mathrm{Q}_{3} \cdot \mathrm{H}\right)$ & 1 \\
\hline$\left(\mathrm{Q}_{3} \cdot \mathrm{L}, \mathrm{Q}_{1} \cdot \mathrm{L}\right)$ & 1 & $\left(\mathrm{Q}_{3} \cdot \mathrm{H}, \mathrm{Q}_{1} \cdot \mathrm{H}\right)$ & 0.61 \\
\hline$\left(\mathrm{Q}_{1} . \mathrm{L}, \mathrm{Q}_{5} . \mathrm{L}\right)$ & 0.49 & $\left(\mathrm{Q}_{1} \cdot \mathrm{H}, \mathrm{Q}_{5} . \mathrm{H}\right)$ & 0.7 \\
\hline$\left(\mathrm{Q}_{5} . \mathrm{L}, \mathrm{Q}_{1} . \mathrm{L}\right)$ & 0.91 & $\left(\mathrm{Q}_{5} \cdot \mathrm{H}, \mathrm{Q}_{1} \cdot \mathrm{H}\right)$ & 0.68 \\
\hline$\left(\mathrm{Q}_{2} . \mathrm{L}, \mathrm{Q}_{3} . \mathrm{L}\right)$ & 0.86 & $\left(\mathrm{Q}_{2} \cdot \mathrm{H}, \mathrm{Q}_{3} \cdot \mathrm{H}\right)$ & 0.9 \\
\hline$\left(\mathrm{Q}_{3} \cdot \mathrm{L}, \mathrm{Q}_{2} . \mathrm{L}\right)$ & 0.86 & $\left(\mathrm{Q}_{3} \cdot \mathrm{H}, \mathrm{Q}_{2} \cdot \mathrm{H}\right)$ & 0.68 \\
\hline$\left(\mathrm{Q}_{2} \cdot \mathrm{L}, \mathrm{Q}_{5} . \mathrm{L}\right)$ & 0.9 & $\left(\mathrm{Q}_{2} . \mathrm{H}, \mathrm{Q}_{5} . \mathrm{H}\right)$ & 0.67 \\
\hline$\left(\mathrm{Q}_{5} . \mathrm{L}, \mathrm{Q}_{2} . \mathrm{L}\right)$ & 0.9 & $\left(\mathrm{Q}_{5} . \mathrm{H}, \mathrm{Q}_{2} . \mathrm{H}\right)$ & 0.79 \\
\hline \multicolumn{4}{|c|}{$\alpha_{1}(2.1), C_{1} \rightarrow L_{1}$} \\
\hline \multicolumn{4}{|c|}{$\rightarrow \alpha_{2}(1.89) \rightarrow N P L S_{1} \rightarrow C_{2} \rightarrow L_{2}$} \\
\hline & \multicolumn{3}{|c|}{$\rightarrow \alpha_{3}(1.79) \rightarrow N P L S_{2} \rightarrow C_{3} \rightarrow L_{3}$} \\
\hline & \multicolumn{3}{|c|}{$\rightarrow \alpha_{4}(1.72) \rightarrow N P L S_{4} \rightarrow C_{4} \rightarrow L_{4}$} \\
\hline & \multicolumn{3}{|c|}{$\rightarrow \alpha_{5}(1.66) \rightarrow \mathrm{NPLS}_{5}(\mathrm{Null})$} \\
\hline
\end{tabular}

Fig. 6. The process of mining association rules

In the process of data mining, only any two items both with high grades or both with low grades would be considered as a 2-large itemset, because if one with high grades and the other with low grades, the found embedded information is meaningless for teachers. However, teachers cannot explain why students do not learn well for some specific quizzes according to the output of first phase. In other words, we cannot intuitively induce what learning concepts the students miss in accordance with the information about association rules of the quizzes, although information about what concepts are contained in quizzes is known. Therefore, we apply inductive machine learning strategy, AQR algorithm [8], to find the missing learning concepts. 


\subsection{Inductive Learning Algorithm}

$\mathrm{AQR}$ is one kind of the batch and inductive learning algorithm [8] that uses the basic AQ algorithm [11] to generate the concept description, which can include all positive instances and exclude all negative instances. When learning process is running, AQR performs a heuristic search through the hypothesis space to determine the description. The training instances, including the set of positive instances and the set of negative instances, are learned in stages; each stage generates a single concept description, and removes the instances it covers from the training set. The step is repeated until enough concept descriptions have been found to cover all positive instances.

In the first phase of the Two-Phase Fuzzy Mining and Learning Algorithm, LFMAlg is used to find the association rules embedded in the historical learning records of students. The large itemsets except 1-large itemset can be considered as the training instances for $\mathrm{AQR}$ algorithm. Because the large itemsets of low grades, the missing concepts, can be considered as positive instances of the training instances, and because the large itemsets of high grades can be considered as negative instances, the concept descriptions which include/exclude all positive/negative instances can show the more precise missing concepts of students. The association rule of the first phase's output consists of the left-hand-side (LHS) and right-hand-side (RHS). The LHS may consist of one or more items. To transform the LHS into the training instance, the union operator for the concepts contained by the items of LHS is used. For example, the item $\left(\mathrm{Q}_{1} . \mathrm{L}, \mathrm{Q}_{3} . \mathrm{L}, \mathrm{Q}_{4} . \mathrm{L}\right)$ is one of 3-large itemset, and the confidence $\lambda$ is larger than the defined minimum confidence threshold. Then the itemset can be transformed into a positive instance by run the union operator for $\mathrm{Q}_{1}$ 's and $\mathrm{Q}_{3}$ 's learning concepts shown in Table 2, i.e., $(10010,10000)=(10010)$. To combine the learning concept of RHS of this item, $\mathrm{Q}_{4}$, the positive instance can be expressed as (10010, 01100).

Before using AQR algorithm to induce the concept descriptions, which cover missing concepts, the pre-process of transforming the itemsets found by the first phase into the training instances should be done as mentioned above.

The concepts derived from $A Q R$ are represented as the multiple-valued logic calculus with typed variables, which can be represented as follows.

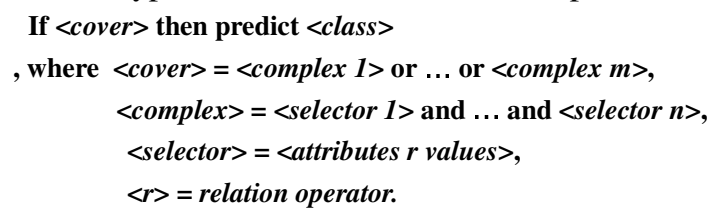

A selector relates a variable to a value or a disjunction of values. A conjunction of selectors forms a complex. A cover is a disjunction of complexes describing all positive instances and none of the negative ones of the concept. The AQR algorithm is described as below.

\section{AQR Algorithm [8]}

Input: The set of positive instances and the set of negative instances.

Output: The information of missing concepts. 
SETP1: Let $P O S$ be a set of positive instances and let $N E G$ be a set of negative instances.

SETP2: Let COVER be the empty cover.

SETP3: While COVER does not cover all instances in POS, process the following steps. Otherwise, stop the procedure and return COVER.

SETP4: Select a SEED, i.e., a positive instance not covered by COVER.

SETP5: Call procedure GENSTAR to generate a set STAR, which is a set of complex that covers $S E E D$ but that covers no instances in NEG.

SETP6: Let BEST be the best complex in STAR according to the user-defined criteria.

SETP7: Add BEST as an extra disjunction of COVER.

GENSTAR procedure

SETP1: Let STAR be the set containing the empty complex.

SETP2: While any complex in STAR covers some negative instances in $N E G$, process the following steps. Otherwise, stop the procedure and return STAR.

SETP3: Select a negative instance $E_{n e g}$ covered by a complex in STAR

SETP4: Specialize complexes in STAR to exclude $E_{n e g}$ by:

Let EXTENSION be all selectors that cover SEED, but not $E_{n e g}$.

Let STAR be the set $\{\mathrm{x} \cap \mathrm{y} \mid \mathrm{x} \in S T A R, \mathrm{y} \in$ EXTENSION $\}$

SETP5: Repeat this step until sizes of $S T A R \leq$ max-star (a user-defined maximum). Remove the worst complex from STAR.

\section{Example 4.2}

Table 5 shows the training instances of transforming the 2-large itemsets, in which support value are larger than the defined minimum confidence threshold.

Table 5. An example of training instances

\begin{tabular}{|c|c|c||c|c|c|}
\hline Itemset & $\begin{array}{c}\text { Positive (+)/ } \\
\text { Negative (-) }\end{array}$ & Instance & Itemset & $\begin{array}{c}\text { Positive (+)/ } \\
\text { Negative (-) }\end{array}$ & Instance \\
\hline$\left(\mathrm{Q}_{2} \cdot \mathrm{L}, \mathrm{Q}_{1} \cdot \mathrm{L}\right)$ & + & $(10100,10010)$ & $\left(\mathrm{Q}_{2} \cdot \mathrm{L}, \mathrm{Q}_{5} \cdot \mathrm{L}\right)$ & + & $(10100,01001)$ \\
\hline$\left(\mathrm{Q}_{3} \cdot \mathrm{L}, \mathrm{Q}_{1} \cdot \mathrm{L}\right)$ & + & $(10000,10010)$ & $\left(\mathrm{Q}_{5} \cdot \mathrm{L}, \mathrm{Q}_{2} \cdot \mathrm{L}\right)$ & + & $(01001,10100)$ \\
\hline$\left(\mathrm{Q}_{5} \cdot \mathrm{L}, \mathrm{Q}_{1} \cdot \mathrm{L}\right)$ & + & $(01001,10010)$ & $\left(\mathrm{Q}_{1} \cdot \mathrm{H}, \mathrm{Q}_{2} \cdot \mathrm{H}\right)$ & - & $(10010,10100)$ \\
\hline$\left(\mathrm{Q}_{2} \cdot \mathrm{L}, \mathrm{Q}_{3} \cdot \mathrm{L}\right)$ & + & $(10100,10000)$ & $\left(\mathrm{Q}_{1} \cdot \mathrm{H}, \mathrm{Q}_{3} \cdot \mathrm{H}\right)$ & - & $(10010,10000)$ \\
\hline$\left(\mathrm{Q}_{3} \cdot \mathrm{L}, \mathrm{Q}_{2} \cdot \mathrm{L}\right)$ & + & $(10000,10100)$ & $\left(\mathrm{Q}_{5} \cdot \mathrm{H}, \mathrm{Q}_{2} \cdot \mathrm{H}\right)$ & - & $(01001,10100)$ \\
\hline
\end{tabular}

The three pairs, $(11101,10010),(00100,10000)$, and $(01001,10100)$, which are the learning concepts students do not learn well, are found by the learning process of AQR algorithm. For example, $(00100,10000)$ means that the learning concept, (C), have high degree of relationship with (A), even if (C) may introduce (A). The teachers may analyze learning results of $\mathrm{AQR}$ algorithm as shown in Fig. 7.

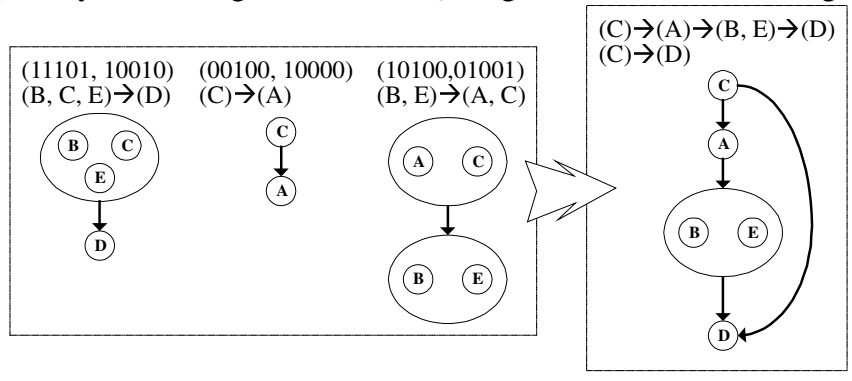

Fig. 7. The analysis of learning results of $A Q R$ algorithm 


\section{Concluding Remarks}

In this work, we proposed the Two-Phase Fuzzy Mining and Learning Algorithm. In the first phase, LMFAlg was proposed to find the embedded association rules from the historical learning records of students. In the second phase, the AQR algorithm was applied to find the concept descriptions indicating the missing concepts during students learning. The obtained results can be fed back to the teachers for analyzing, refining or reorganizing learning path of teaching materials and the tests. Now, we are trying to apply our algorithm to the virtual mathematics curriculum of senior high school in Taiwan.

Acknowledgement. This work was partially supported by the National Science Council of the Republic of China under Grant No. NSC 90-2511-S009-023.

\section{Reference}

1. Agrawal, R., Srikant, R.: Fast Algorithms for Mining Association Rules. Proc. Of the $20^{\text {th }}$ Int'l Conference on Very Large Database. (1994)

2. Alessi, S.-M., Trollip, S.-R.: Computer-based Instruction: Methods and Development. 2nd. Englewood Cliffs, NJ: Prentice-Hall (1991)

3. Antal, P.: Animated Explanations Using Adaptive Student Models. Proc. of INES'97. (1997) 573-576

4. Au, W.-H., Chan, K.-C.-C.,: FARM: A Data Mining System for Discovering Fuzzy Association Rules. Proc. of FUZZ-IEEE'99. 3 (1999) 1217-1222

5. Chen, M.-S., Han, J., Yu, P.-S.: Data Mining: An Overview from A Database Perspective. IEEE Transaction on Knowledge and Data Engineering. 8(6) (1996) 866-883

6. Chen, S.-S., Hsu, P.-Y., Chen, Y.-L.: Mining Web Traversal Rules with Sequences. MIS Review 1(1999) 53-71

7. Chou, C.: A Computer Logging Method for Collecting Use-reported Inputs During Formative Evaluation of Computer Network-assisted Distance Learning. Proc. of EDMedia'96. (1996)

8. Clark, P., Niblett, T.: The CN2 Induction Algorithm. Machine Learning. 3 (1989) 261-283

9. Hong, T.-P., Kuo, C.-S., Chi, S.-C.: A Fuzzy Data Mining Algorithm for Quantitative Values. Proc. of Knowledge-based Intelligent Information Engineering Systems. (1999) 480-483

10. Hwang, G.-J.: A Tutoring Strategy Supporting System for Distance Learning on Computer Networks. IEEE Transactions on Education. 1(4) (1998) 343-343

11. Michalski, R.-S.: On The Quasi-minimal Solution of The General Covering Problem. Proc. of the $5^{\text {th }}$ International Symposium on Information Processing. (1969) 125-128

12. Sun, C.-T., Chou, C.: Experiencing CORAL: Design and Implementation of Distance Cooperative Learning. IEEE Transactions on Education. 39(3) (1996)357-366

13. Su, G.-H., Tseng, S. S., Tsai, C.-J., Zheng, J.-R.: Building An Object-oriented and Individualized Learning Environment on the WWW. Proc. of ICCE'99. (1999) 728-735

14. Su, G.-H., Tseng, S. S., Tsai, C.-J., Zheng, J.-R.: Implementation of An Object-Oriented Learning Environment Based on XML," Proc. of ICCE'00. 2 (2000) 1120-1127

15. Tsai, C.-J., Tseng, S. S., Su, G.-H.: Design of An Object-oriented and Rule-based Virtual School. Proc. of GCCCE'00. (2000) 320-327 